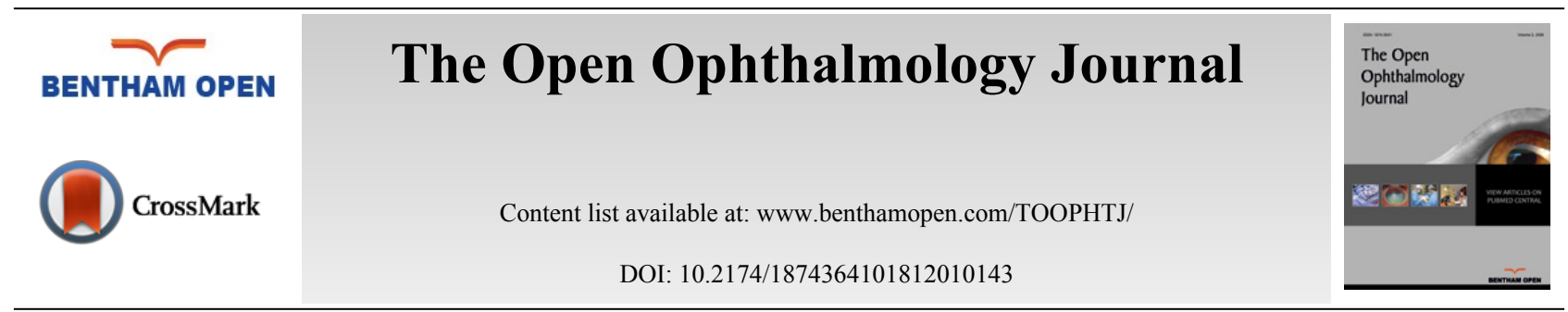

RESEARCH ARTICLE

\title{
Simultaneous Accelerated Corneal Crosslinking and Laser In situ Keratomileusis for the Treatment of High Myopia in Asian Eyes
}

Jin Rong Low, Li Lim*, Jane Chwee Wah Koh, Daniel Kai Peng Chua and Mohamad Rosman

Singapore National Eye Centre, 11 Third Hospital Avenue, Singapore 168751, Singapore

Received: June 06, 2017

Revised: November 25, 2017

Accepted: January 28, 2018

\section{Abstract:}

\section{Background:}

LASIK Xtra is a recently described technique which combines LASIK and accelerated corneal cross-linking(CXL) in the same setting. Its long-term outcome in Asians with high myopia is not well described.

\section{Objectives:}

To compare the efficacy, predictability and safety of LASIK Xtra with LASIK in patients with high myopia.

\section{Method:}

This is a retrospective study comparing 50 consecutive eyes undergoing LASIK Xtra for the correction of high myopia and/or myopic astigmatism (-6.63 to $-15.50 \mathrm{D}$ manifest spherical equivalent) with a matched control group of 50 eyes undergoing LASIK alone for correction of high myopia (-6.00 to $-12.25 \mathrm{D}$ manifest spherical equivalent). Mean follow-up was 5.7 months (range, 1.5-13.3 months) for LASIK Xtra and 3.6 months (range, 1.7-4.2 months) for LASIK only. Outcome measures included Uncorrected Distance Visual Acuity (UDVA), Corrected Distance Visual Acuity (CDVA), refraction and intraoperative and postoperative complications.

\section{Results:}

At post-operative 3 months, all eyes achieved UDVA of 20/40 or better, and 80.0\% of LASIK Xtra eyes achieved UDVA of 20/20 or better, compared to $66.0 \%$ of LASIK only eyes $(p=0.115$ ). Efficacy indices were $0.99 \pm 0.17$ for LASIK Xtra and $0.94 \pm 0.17$ for LASIK only $(p=0.164)$. The proportion of eyes within $\pm 0.50 \mathrm{D}$ of attempted correction was $84 \%$ in the LASIK only group and $72 \%$ in the LASIK Xtra group at post-operative 3 months $(p=0.148)$. Safety indices were $1.11 \pm 0.19$ and $1.11 \pm 0.18$ in the LASIK Xtra and LASIK only groups, respectively $(p=0.735)$.

\section{Conclusion:}

LASIK Xtra achieved comparable safety, predictability and efficacy as LASIK in patients with high myopia. Good refractive stability was attained at 6-12 months. Further long term studies are required to determine whether simultaneous CXL is able to reduce postoperative LASIK keratectasia in high-risk individuals.

Keywords: Corneal crosslinking, Laser in situ keratomileusis, High myopia, Refractive surgery, Keratorefractive surgery, LASIK Xtra.

\section{INTRODUCTION}

Laser in situ Keratomileusis (LASIK) is the most commonly performed keratorefractive surgery for the correction of ametropia. It results in faster visual recovery and causes less discomfort compared to surface ablation techniques

\footnotetext{
* Address correspondence to this author at the Singapore National Eye Centre, 11 Third Hospital Avenue, Singapore 168751, Singapore; Tel: +6562277255; E-mail: lim.li@singhealth.com.sg
} 
such as photorefractive keratectomy [1].

LASIK keratectasia is a rare but serious complication of the LASIK procedure. Although the mechanisms of postoperative LASIK keratectasia remain unclear, LASIK may reduce corneal biomechanical stability by severing structural lamellae in the anterior cornea during creation of the LASIK flap and removing additional structural lamellae during laser ablation, leading to this complication [2]. Risk factors for postoperative LASIK keratectasia include high myopic corrections, thin corneas and low residual corneal bed thickness [3].

Treatment options for postoperative LASIK keratectasia include rigid gas permeable contact lenses, intrastromal corneal ring segments, and penetrating or lamellar keratoplasty [4]. Corneal collagen cross-linking (CXL), which has been shown to be effective in halting the progression of keratoconus [5], has recently been reported to be successful in slowing or stopping postoperative LASIK keratectasia progression [6 - 9]. Crosslinking causes photopolymerization of corneal stromal fibers by the combined action of a photosensitizing substance (riboflavin) and Ultraviolet-A (UVA) light. This results in formation of new intrafibrillar and interfibrillar covalent bonds among stromal collagen fibers, which increases the rigidity of the corneal collagen and its resistance to deformation [10]. Accelerated CXL, which utilizes increased irradiation intensity, may be a better alternative to standard CXL for it shortens the procedure time and provides more patient comfort [11].

LASIK Xtra is a recently described technique which combines LASIK and accelerated CXL in the same setting. There are limited studies in the literature which evaluate the outcomes of LASIK Xtra and even fewer that evaluate long-term outcomes in Asians with high myopia. A few studies have reported that LASIK Xtra may confer additional benefits of early refractive and keratometric stability after LASIK, improving the predictability of refractive outcomes in patients with high myopia [12 - 14]. In this study, we aim to compare the efficacy, predictability and safety of LASIK Xtra with LASIK in Asians with high myopia.

\section{MATERIAL AND METHODS}

In this retrospective study, 50 consecutive eyes of 26 patients undergoing LASIK Xtra for the correction of high myopia and/or myopic astigmatism, defined as myopia greater than -6.00 diopters (D) of spherical equivalent, were recruited at the Laser Vision Centre, Singapore National Eye Centre (SNEC), from April 2013 to December 2015. These were compared with a matched group of 50 eyes of 36 patients which had undergone LASIK alone for the correction of high myopia (greater than -6.00 D) during the same period. Patients returned for 1 day, 1 week, 1 month, and 3 month follow-up after the initial procedure for both the LASIK only and LASIK Xtra groups. A longer follow-up was obtained for the LASIK Xtra group. A comprehensive 100\% clinical audit of all LASIK and LASIK Xtra cases in SNEC was performed independently by our Clinical Audit Department. The study was approved by the Sing Health Centralised Institutional Review Board.

Inclusion criteria for surgery were no soft contact lens wear for 1 week before surgery and rigid contact lens wear for 3 weeks prior; stable refractive error for 12 months before surgery; normal peripheral retina or after prophylactic treatment with photocoagulation; no previous ocular surgery, no corneal diseases, no glaucoma; and no history of ocular trauma. Exclusion criteria for surgery were keratoconus or forme fruste keratoconus as evidenced by corneal topography, active ocular or systemic disease likely to affect corneal wound healing, pregnancy, or nursing females. Patients requiring monovision correction were also excluded.

All cases were performed by two surgeons (LL and MR). The cases had a 100-110 $\mu \mathrm{m}$ LASIK flap created with the IntraLase IFS femtosecond laser (Abbott Medical Optics, Irvine, CA) and LASIK ablation using either the WaveLight EX500 (Alcon Laboratories, Fort Worth, TX) or WaveLight Allegretto Wave Eye-Q 400Hz (Alcon Laboratories, Fort Worth, TX), wavefront optimised profile. The nomogram supplied by the WaveLight EX500 was used for all cases of LASIK and LASIK Xtra, with a refractive target of plano to $+0.5 \mathrm{D}$ for all cases.

Pre-operatively, we evaluated Uncorrected Distance Visual Acuity (UDVA), Corrected Distance Visual Acuity (CDVA), subjective refraction, corneal topography on Orbscan II corneal topography system (Bausch \& Lomb Surgical, Orbtek Inc, Salt Lake City, Utah, USA), and Endothelial Cell Counts (ECC) (Konan Medical Corporation, Hyogo, Japan) (only for LASIK Xtra eyes). Analyses were performed for all cases at post-operative 3 months, and for LASIK Xtra cases at post-operative 6 to 12 months.

The efficacy of the surgeries was evaluated by computing the proportion of cases which achieved UDVA of 20/40 or better, and 20/20 or better, and the efficacy index (ratio between postoperative UDVA and preoperative CDVA). The predictability of the surgeries was evaluated by computing the proportion of cases within $1.0 \mathrm{D}$ and within $0.5 \mathrm{D}$ of 
attempted refractive correction. The safety of the surgeries was evaluated by recording any intra-operative or postoperative complications and by computing the proportion of cases with improved or unchanged post-operative CDVA compared to pre-operative CDVA, and the safety index (ratio between post-operative CDVA and pre-operative CDVA).

\subsection{Surgical Technique}

For LASIK Xtra, after completion of the LASIK excimer ablation procedure, VibeX Xtra (Avedro, Inc., Waltham, MA, USA), consisting of $0.22 \%$ saline-diluted riboflavin solution, was placed on the bare stromal bed, and left to soak in for 45 seconds. Special care was taken not to allow the riboflavin solution to come into contact with the LASIK flap. After the 45-second riboflavin soak, the stromal bed was copiously irrigated to remove residual VibeX Xtra, and the LASIK flap was repositioned. Following flap repositioning, UVA fluence of $30 \mathrm{~mW} / \mathrm{cm}^{2}$ was applied for 46 seconds (total energy $1.4 \mathrm{~J} / \mathrm{cm}^{2}$ ), provided by the $\mathrm{KXL}^{\circledR} \mathrm{CXL}$ system (Avedro, Inc., Waltham, MA, USA). These parameters were recommended by Avedro and have also been used in another study [12].

A bandage contact lens was then placed on the ocular surface and the patient was treated with topical moxifloxacin (Vigamox $^{\circledR}$, Alcon Laboratories, Inc, Fort Worth, TX, USA), dexamethasone phosphate 0.1\% (Maxidex ${ }^{\circledR}$, Alcon Laboratories, Inc, Fort Worth, TX, USA), and hypromellose $0.3 \%$ and dextran $0.1 \%$ (Tears Naturale Free ${ }^{\circledR}$, Alcon Laboratories, Fort Worth, TX, USA). Patients were followed up on the first post-operative day and the contact lens was removed during that visit. Further follow-up examinations were performed at the end of week 1 and months 1 and 3 after surgery for both groups. A longer follow-up of 6-12 months was obtained for the LASIK Xtra group.

\subsection{Statistical Analysis}

Data were analysed using Statistical Package for Social Sciences (SPSS) Version 20.0 (IBM SPSS Statistics for Windows, Armonk, NY: IBM Corp., 2011). Fisher's Exact Test was used to analyse the efficacy and predictability of the surgeries. Independent Sample T-Test and Non-parametric Mann-Whitney Test were used to analyse the spherical equivalent, efficacy index and safety index.

\section{RESULTS}

\subsection{Baseline Patient Characteristics}

The mean age was $31 \pm 7$ years (range, 22-46 years) and 31 \pm 7 years (range, 21-56 years) for the LASIK Xtra group and LASIK only group, respectively. Fifteen (57.7\%) patients in the LASIK Xtra group and $21(58.3 \%)$ patients in the LASIK only group were female. The majority of patients in both groups were Chinese $(68 \%$ in the LASIK Xtra group and $86 \%$ in the LASIK only group) and female (58\% in both groups). There was no statistically significant difference between the groups in terms of age $(p=0.236)$, ethnicity $(p=0.274)$, gender $(p=0.960)$ and laterality $(p=0.688)$.

Myopia ablation treatment was performed on 50 eyes (100\%) and 25 eyes (50\%) with the Wavelight EX500 (Alcon Laboratories, Fort Worth, TX) for LASIK Xtra and LASIK only groups, respectively. Twenty-five eyes (50\%) in the LASIK only group and none in the LASIK Xtra group were treated with the WaveLight Allegretto Wave Eye-Q 400Hz (Alcon Laboratories, Fort Worth, TX).

The mean follow-up was 5.7 months (range, 1.5-13.3 months) for the LASIK Xtra group and 3.6 months (range, 1.7-4.2 months) for the LASIK only group. All eyes had a mean follow-up of 3 months, while 27 eyes in the LASIK Xtra group had mean follow-up of 6-12 months. Comparison of visual outcome between the two groups was performed at 1 and 3 months' follow-up.

\subsection{Refraction Spherical Equivalent}

For the LASIK Xtra group, the pre-operative mean spherical equivalent was $-9.45 \pm 1.83 \mathrm{D}$ (range, -6.63 to $-15.50 \mathrm{D}$ ) (Table 1). The attempted correction mean spherical equivalent was $-9.40 \pm 1.47 \mathrm{D}$ (range, -6.88 to $-13.50 \mathrm{D}$ ). The mean spherical equivalent were $+0.36 \pm 0.42 \mathrm{D}$ (range, -0.50 to $+1.25 \mathrm{D}$ ) and $+0.33 \pm 0.46 \mathrm{D}$ (range, -0.38 to $+1.25 \mathrm{D})$ at postoperative 3 months and post-operative 6 to 12 months, respectively. Stability of spherical equivalent refractive outcome at post-operative 6 to 12 months was achieved in the LASIK Xtra group with no regression $(p=0.243)$ (Fig. 1).

For the LASIK only group, pre-operative mean spherical equivalent was $-9.42 \pm 0.97 \mathrm{D}$ (range, -6.00 to $-12.25 \mathrm{D}$ ). The attempted correction mean spherical equivalent was $-9.56 \pm 0.86 \mathrm{D}$ (range, -7.00 to $-11.63 \mathrm{D}$ ). The mean spherical equivalent at post-operative 3 months was $+0.26 \pm 0.34 \mathrm{D}$ (range, -0.25 to $+1.00 \mathrm{D}$ ) (Fig. 2). 
There was no statistically significant difference between the LASIK Xtra and LASIK only groups in terms of preoperative mean spherical equivalent $(p=0.785)$ and attempted correction mean spherical equivalent $(p=0.497)$. At postoperative 3 months, the mean spherical equivalent were $+0.36 \pm 0.42 \mathrm{D}$ and $+0.26 \pm 0.34 \mathrm{D}$ in the LASIK Xtra group and LASIK only group, respectively $(p=0.243)$.

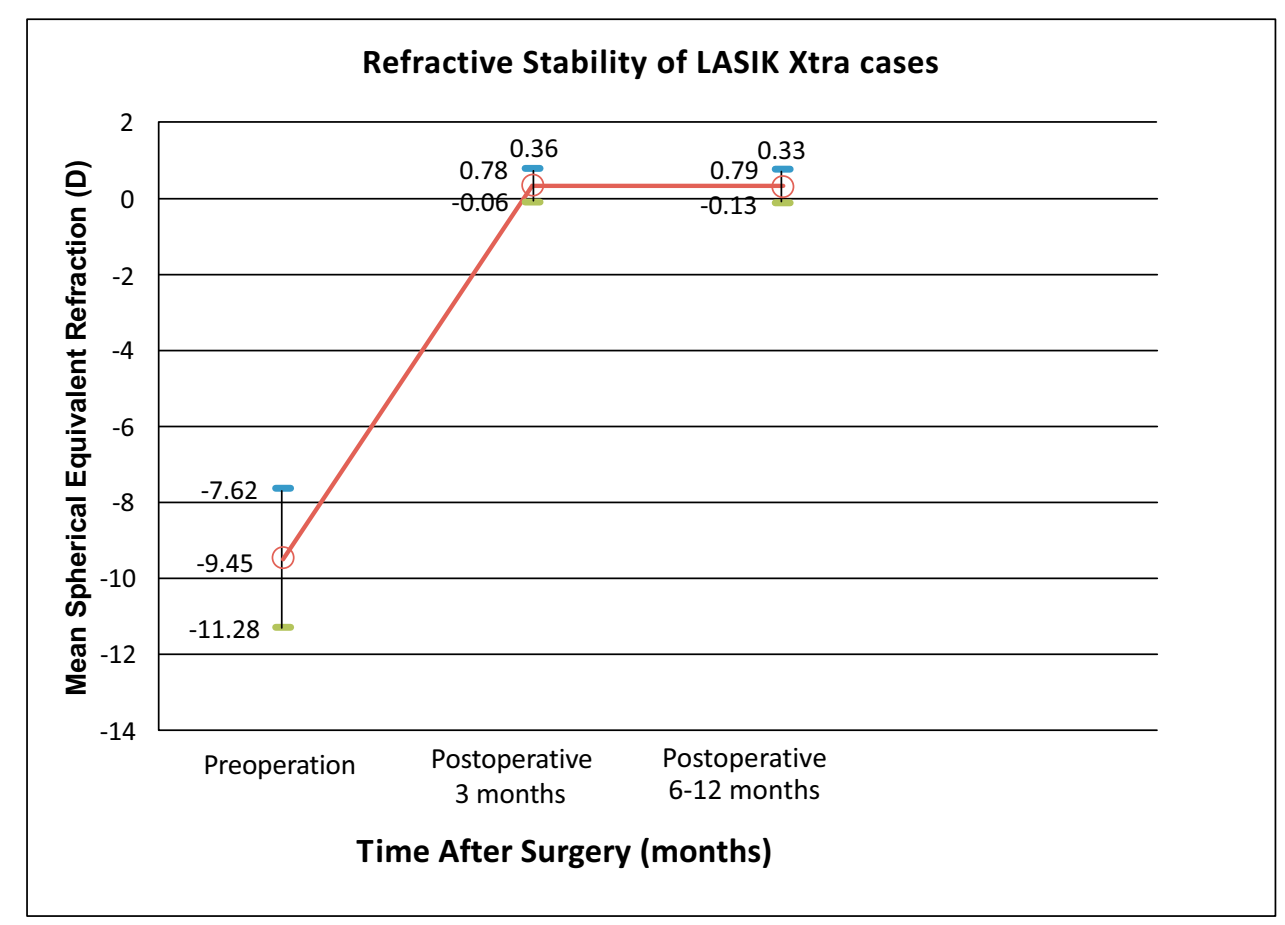

Fig. (1). The 6 to12-month stability of spherical equivalent refractive outcome with standard error bars in highly myopic eyes treated with LASIK Xtra.

\section{Refractive Stability of LASIK cases}

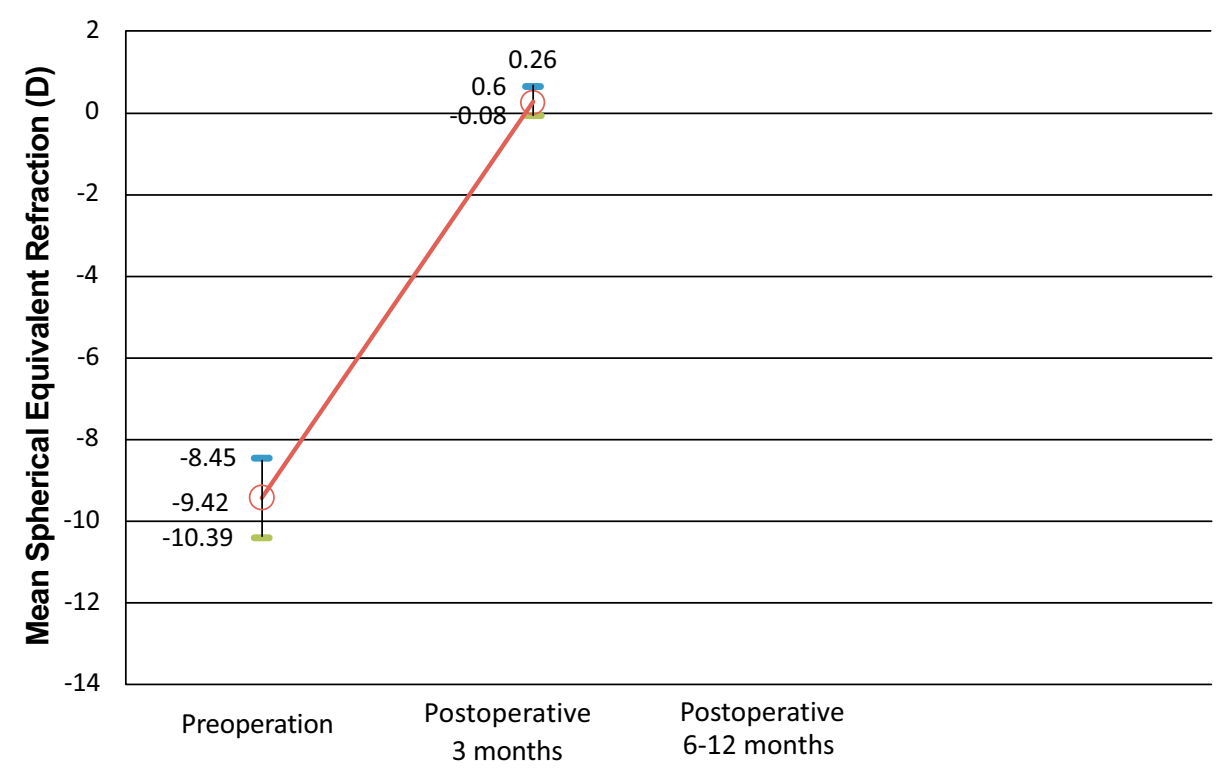

Time After Surgery (months)

Fig. (2). The 3-month stability of spherical equivalent refractive outcome with standard error bars in highly myopic eyes treated with LASIK only. 
Table 1. Pre-operative, attempted and post-operative spherical equivalent refraction for LASIK only and LASIK Xtra groups.

\begin{tabular}{|c|c|c|c|}
\hline - & LASIK only & LASIK Xtra & P value \\
\hline Pre-operative SE (D) & $-9.42 \pm 0.97$ & $-9.45 \pm 1.83$ & \multirow{2}{*}{0.785} \\
\hline Pre-operative range (D) & -6.00 to -12.25 & -6.63 to -15.50 & \\
\hline Attempted SE (D) & $-9.56 \pm 0.86$ & $-9.40 \pm 1.47$ & \multirow{2}{*}{0.497} \\
\hline Attempted range (D) & -7.00 to -11.63 & -6.88 to -13.50 & \multirow{2}{*}{0.243} \\
\hline Post-operative 3 months SE (D) & $+0.26 \pm 0.34$ & $+0.36 \pm 0.42$ & \\
\hline Post-operative 3 months range (D) & -0.25 to +1.00 & -0.50 to +1.25 & \\
\hline Post-operative 6-12 months SE (D) & - & $+0.33 \pm 0.46$ & -0.38 to +1.25 \\
\hline
\end{tabular}

$\mathrm{SE}=$ Spherical equivalent; $\mathrm{D}=$ Diopter.

Data are mean \pm standard deviation unless otherwise indicated.

\subsection{Efficacy}

The proportion of eyes with pre-operative CDVA of $20 / 20$ or better was $98.0 \%$ and $96.0 \%$ in the LASIK Xtra and LASIK only groups respectively, and this was not statistically significantly different $(p=1.000)$. At post-operative 3 months, all eyes achieved UDVA of 20/40 or better, and $80.0 \%$ of LASIK Xtra eyes achieved UDVA of 20/20 or better, compared to $66.0 \%$ of LASIK only eyes $(p=0.115$ ) (Figs. 3 and 4$)$. The efficacy indices were $0.99 \pm 0.17$ for LASIK Xtra and $0.94 \pm 0.17$ for LASIK only $(p=0.164)$.

At post-operative 6 to 12 months, all LASIK Xtra eyes achieved UDVA of 20/40 or better and $66.7 \%$ of them achieved UDVA of 20/20 or better, resulting in an efficacy index of $0.95 \pm 0.16$.

\subsection{Predictability}

Figs. (5 and 6) show the spherical equivalent refractive accuracy at post-operative 3 months for the LASIK only group and at post-operative 3 and 6 to 12 months for the LASIK Xtra group. A greater percentage of eyes were within $\pm 0.50 \mathrm{D}$ of the attempted correction in the LASIK only group (84.0\%) than in the LASIK Xtra group (72.0\%) at postoperative 3 months ( $p=0.148$ ). Similarly, $100 \%$ of eyes in the LASIK only group were within $\pm 1.00 \mathrm{D}$ of the attempted correction, compared to $96.0 \%$ of eyes in the LASIK Xtra group $(p=0.495)$.

\section{Efficacy: LASIK only}

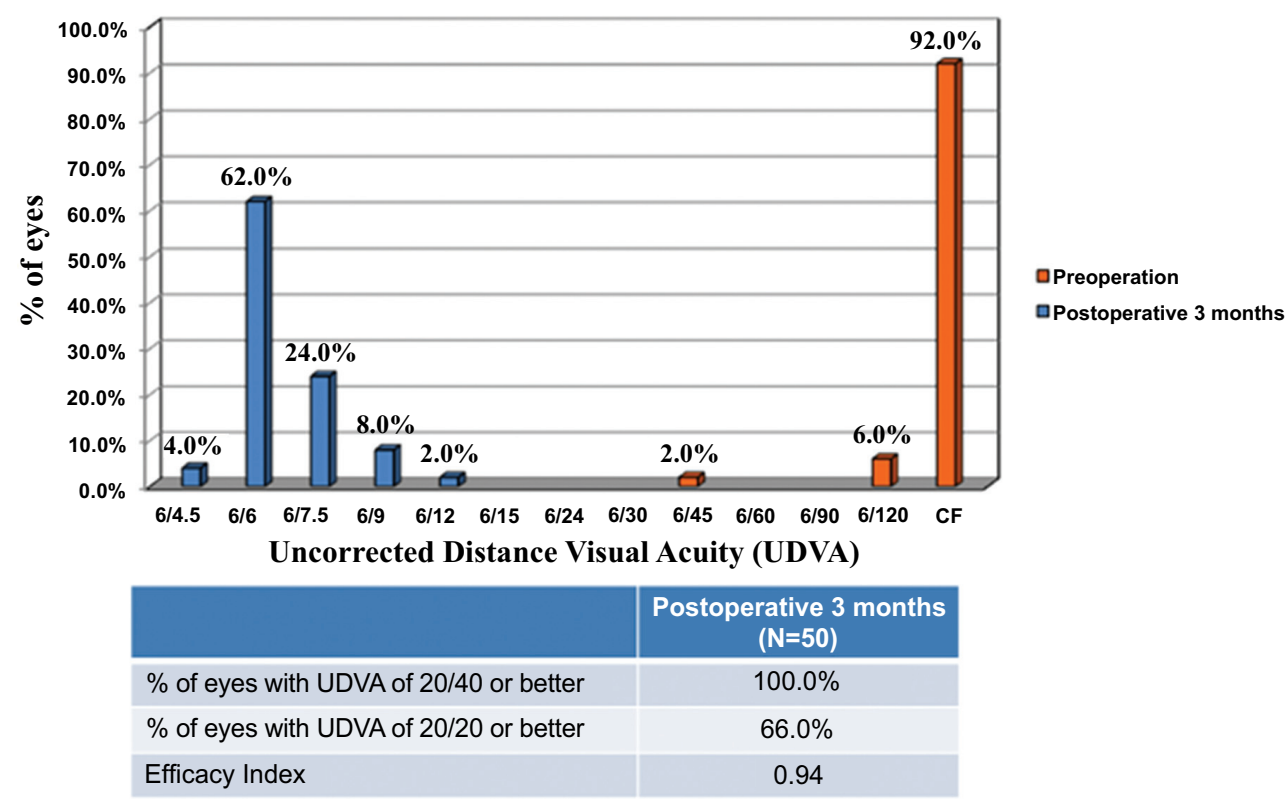

Fig. (3). Pre-operative (orange) and 3-month post-operative (light blue) uncorrected distance visual acuity in highly myopic eyes treated with LASIK only. 


\section{Efficacy: LASIK Xtra}

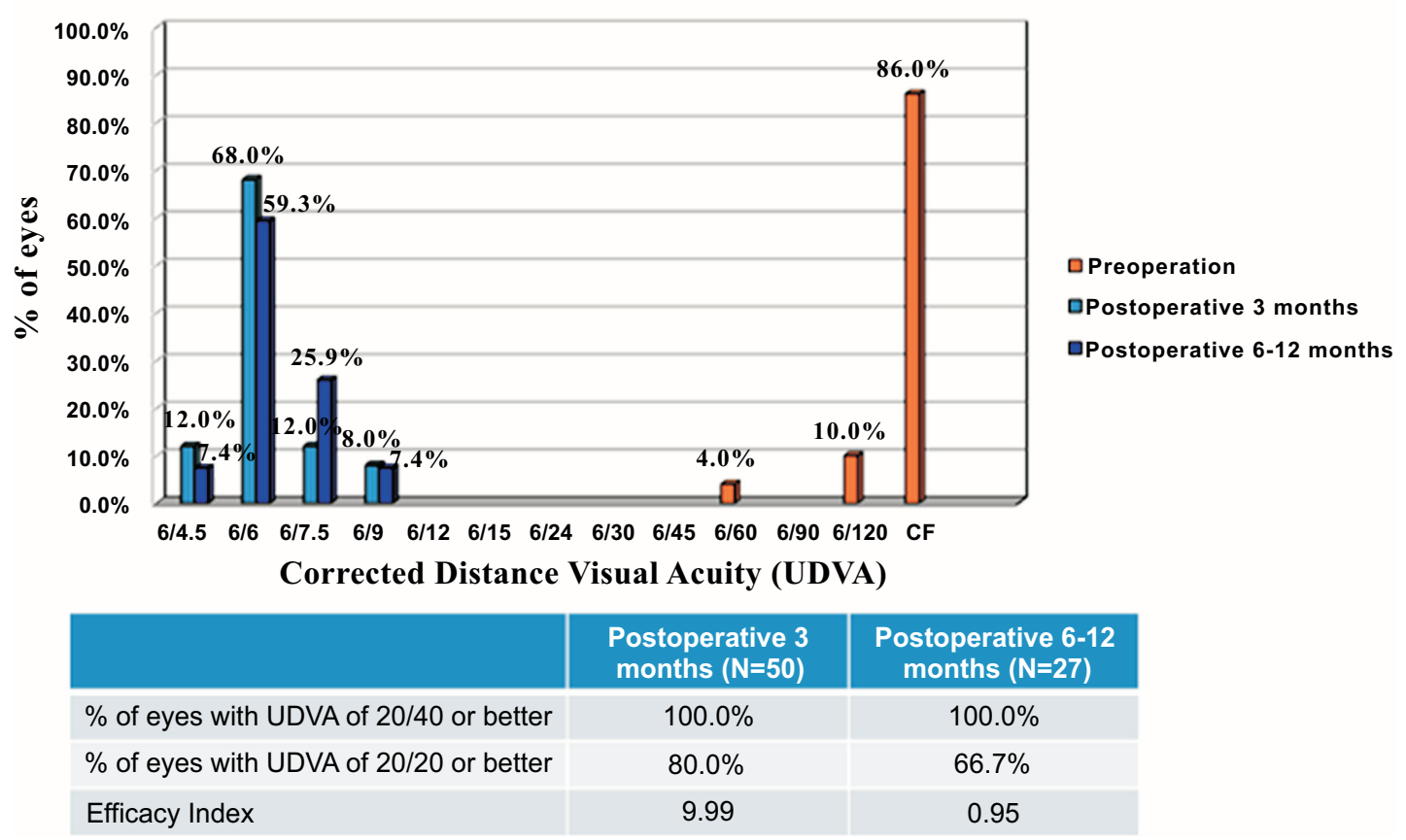

Fig. (4). Pre-operative (orange), 3-month post-operative (light blue) and 6 to 12-month post-operative (dark blue) uncorrected distance visual acuity in highly myopic eyes treated with LASIK Xtra.

At post-operative 6 to 12 months, $95.2 \%$ of eyes in the LASIK Xtra group were within $\pm 1.00 \mathrm{D}$ of the attempted correction, and $71.4 \%$ of them were within $\pm 0.50 \mathrm{D}$ of the attempted correction.
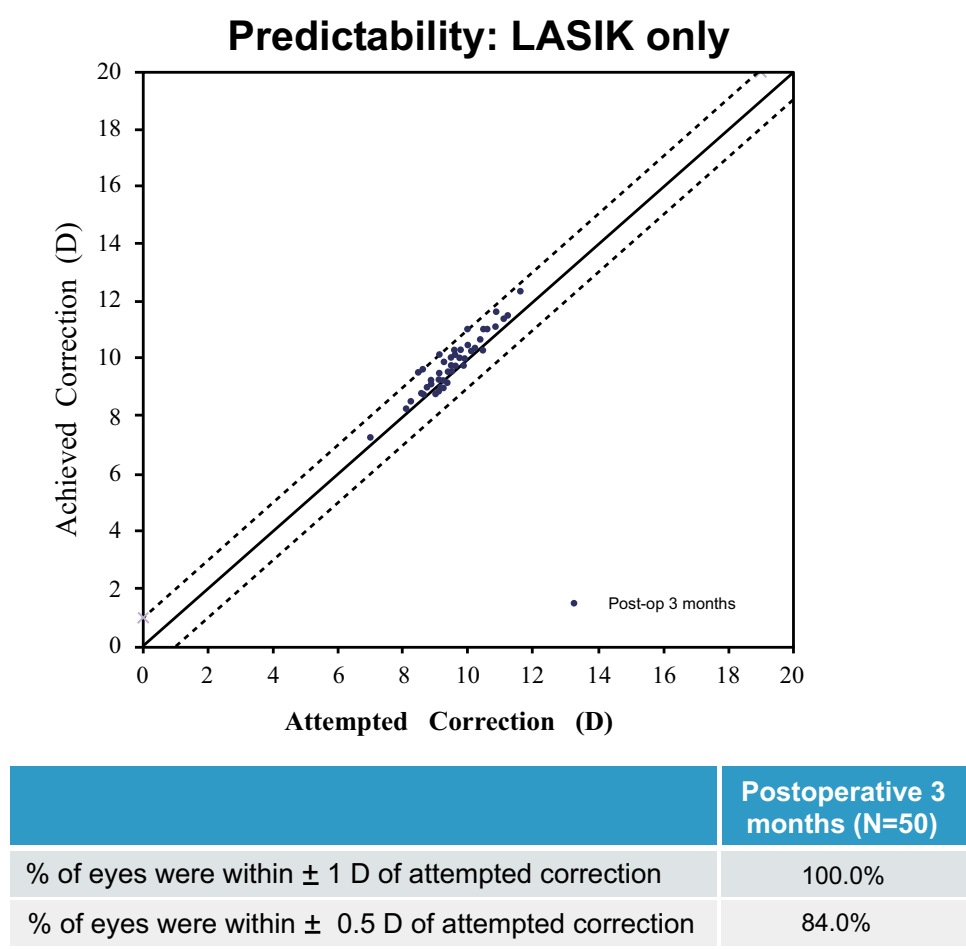

Fig. (5). Scatterplot of the spherical equivalent of the attempted correction versus achieved refractive outcome in highly myopic eyes treated with LASIK only at post-operative 3 months. 


\section{Predictability: LASIK Xtra}

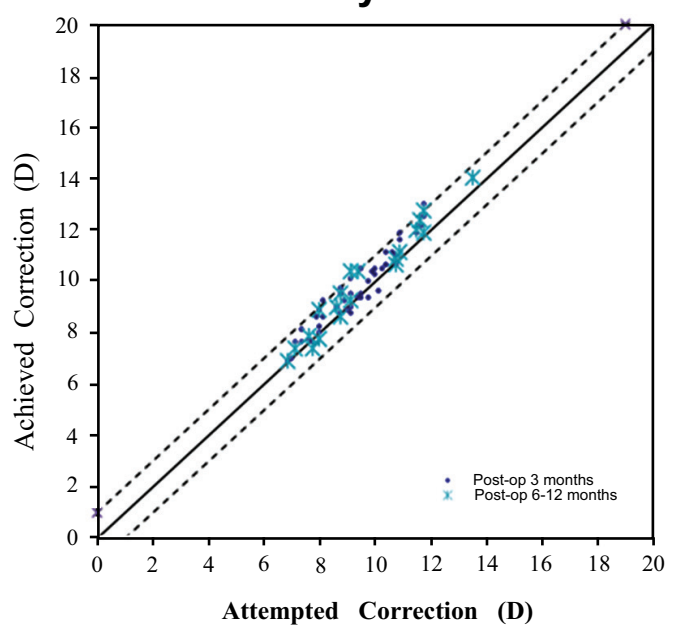

\begin{tabular}{|c|c|c|}
\hline & $\begin{array}{l}\text { Postoperative } 3 \\
\text { months }(\mathrm{N}=50)\end{array}$ & $\begin{array}{c}\text { Postoperative 6-12 } \\
\text { months }(\mathrm{N}=21)\end{array}$ \\
\hline$\%$ of eyes were within $\pm 1 \mathrm{D}$ of attempted correction & $96.0 \%$ & $95.2 \%$ \\
\hline$\%$ of eyes were within $\pm 0.5 \mathrm{D}$ of attempted correction & $72.0 \%$ & $71.4 \%$ \\
\hline
\end{tabular}

Fig. (6). Scatterplot of the spherical equivalent of the attempted correction versus achieved refractive outcome in highly myopic eyes treated with LASIK Xtra at post-operative 3 (dark blue dot) and 6-12 months (light blue cross).

\subsection{Safety}

The safety index was the same in the LASIK Xtra group $(1.11 \pm 0.19)$ and the LASIK only group $(1.11 \pm 0.18)$ at postoperative 3 months $(p=0.735)$. At post-operative 3 months, $20(40.0 \%)$ LASIK Xtra eyes and $18(36.0 \%)$ LASIK only eyes achieved a 1 Snellen line gain in CDVA, while $1(2.0 \%)$ LASIK only eye achieved 2 Snellen lines gain in CDVA. No change in CDVA was found in $25(50.0 \%)$ LASIK Xtra eyes and 30 (60.0\%) LASIK only eyes. A decrease in 1 Snellen line of CDVA was found in $5(10.0 \%)$ LASIK Xtra eyes, and a decrease in 2 Snellen lines of CDVA in 1 $(2.0 \%)$ LASIK only eye (Figs. 7 and 8 ).

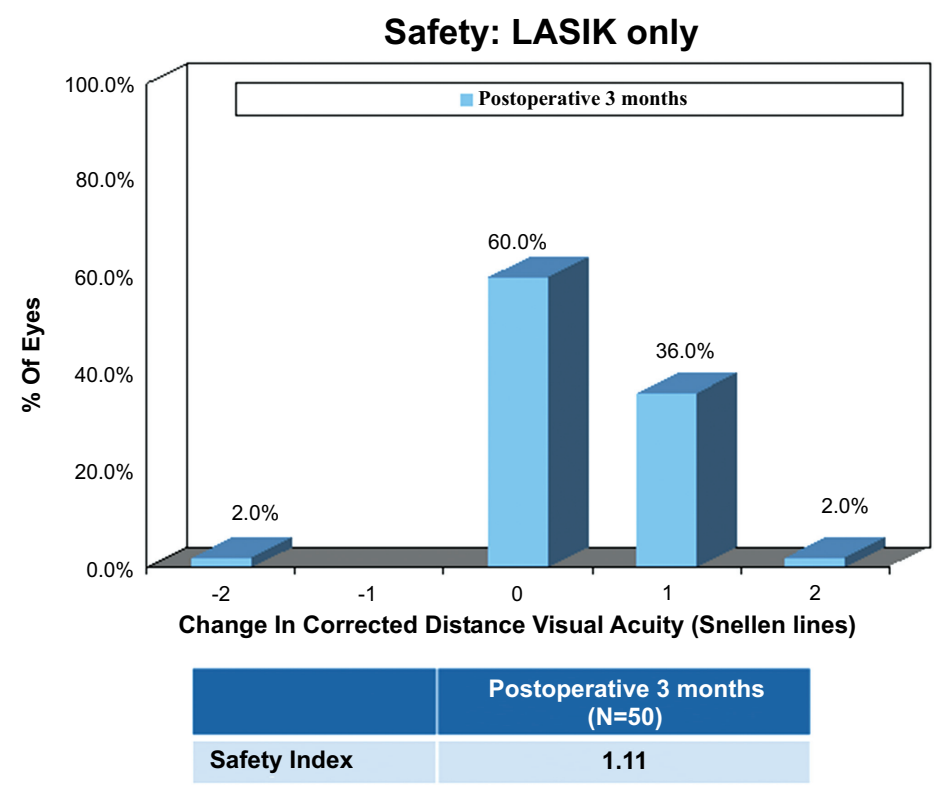

Fig. (7). Change in Snellen lines of corrected distance visual acuity in highly myopic eyes treated with LASIK only at post-operative 3 months. 
Safety: LASIK Xtra

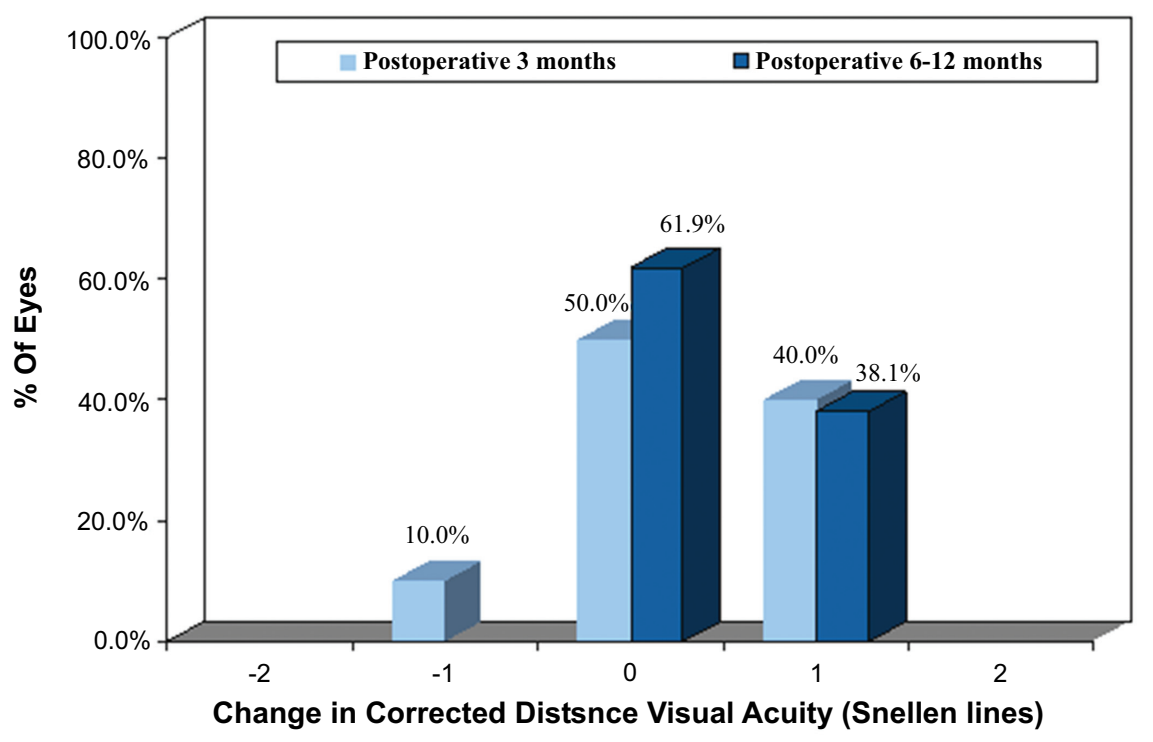

\begin{tabular}{|l|c|c|}
\hline & $\begin{array}{c}\text { Postoperative 3 months } \\
(\mathrm{N}=50)\end{array}$ & $\begin{array}{c}\text { Postoperative 6-12 months } \\
(\mathrm{N}=21)\end{array}$ \\
\hline Safety Index & 1.11 & 1.13 \\
\hline
\end{tabular}

Fig. (8). Change in Snellen lines of corrected distance visual acuity in highly myopic eyes treated with LASIK Xtra at post-operative 3 (light blue) and 6-12 months (dark blue).

The safety index was slightly higher at $1.13 \pm 0.16$ in the LASIK Xtra group at post-operative 6 to 12 months. A gain in 1 Snellen line of CDVA was achieved in 8 (38.1\%) LASIK Xtra eyes. There was no Snellen line lost for the LASIK Xtra group at post-operative 6 to 12 months. Post-operative recovery was generally uneventful with no major adverse events observed in either group. Mild post-operative haze was noted in 5 (10.0\%) LASIK Xtra eyes, which resolved by the last follow-up visit in 3 of these eyes. 3 of the 5 eyes in the LASIK Xtra group which lost 1 line of CDVA returned for the post-operative 6 months follow-up. Of these, 2 had 1 line of CDVA improvement and 1 remained unchanged compared to the pre-operative CDVA.

Grade 1 diffuse lamellar keratitis was found in 4 (8.0\%) LASIK Xtra eyes and all resolved by the second postoperative day. In the LASIK Xtra group, ECC remained stable post-operatively (2893 \pm 304$)$, with no statistically significant difference compared to the pre-operative ECC $(3010 \pm 299)(p=0.755)$ (Table 1).

\section{DISCUSSION}

The development of progressive postoperative LASIK keratectasia is rare but visually debilitating to the patient. LASIK is challenging in patients with high myopia due to the higher risk of developing post-operative keratectasia and refractive regression. The difficulty of determining who is at marginal risk of postoperative LASIK keratectasia coupled with the regression of LASIK correction over time, particularly in younger patients and those with high myopic corrections, makes it a major challenge. $[3,15,16]$ Hence, the use of simultaneous accelerated CXL and LASIK to stabilize the patient's refraction and cornea immediately after LASIK may be useful, particularly in these high-risk patients.

Long-term studies evaluating the use of CXL to treat keratoconus have shown that it can stabilize keratoconic corneas for more than 3 years. [17, 18] Although we are unaware of any study in literature reporting long term outcomes of LASIK Xtra in Asians with high myopia, one may anticipate that CXL in a non-diseased eye would result in similar stabilization. In a small series of 24 Asian patients with low myopia, Tomita et al has reported comparable refractive and keratometric stability in LASIK Xtra and LASIK only at 1 year follow-up [19].

Compared to accelerated CXL for keratoconus which requires a longer riboflavin soak time and utilizes a higher total dose intensity of about $5.4 \mathrm{~J} / \mathrm{cm}^{2}$ and a longer irradiation time, LASIK Xtra requires a shorter riboflavin soak time of 45 seconds and uses lower parameters with a total dose intensity of $1.4 \mathrm{~J} / \mathrm{cm}^{2}$ and irradiation time of 46 seconds. The 
LASIK process provides a natural opportunity for CXL to be performed with minimal interruption to the flow of the procedure. As the LASIK flap is already open, direct application of riboflavin to the corneal stromal bed bypasses the epithelial barrier, thus allowing rapid diffusion of riboflavin into the surrounding stromal tissue. It was found in a study [12] that the addition of CXL to the LASIK procedure did not increase the total procedure time. In our study, the procedure time was increased by 2-3 minutes.

In a prospective study comparing 73 LASIK Xtra eyes and 82 LASIK only eyes, Kanellopoulos et al found that $90.4 \%$ of LASIK Xtra eyes had UDVA of 20/20 or better as compared to $85.4 \%$ of LASIK only eyes at post-operative month $12(p=0.042)$. [13] Tan et al, compared 70 LASIK Xtra eyes and 64 LASIK only eyes in their series of Asian eyes and found that $98 \%$ of LASIK Xtra eyes achieved UDVA of $20 / 25$ or better as compared to $61 \%$ of LASIK only eyes at post-operative month $3(p<0.001)$. [12] These findings were similarly shown in a small prospective study comparing LASIK Xtra in one eye and LASIK only in the fellow eye over a 12-month period. [20] In our study, the LASIK Xtra eyes were also found to have superior UDVA at postoperative month 3 , and better efficacy index compared to LASIK only eyes, although not statistically significant. While our study groups were matched in terms of baseline patient characteristics, the study by Tan et al had a significant difference between the LASIK Xtra and LASIK only groups in terms of age $(p=0.014)$. [12] The younger mean age in the LASIK Xtra group (31.29 \pm 8.44$)$ compared to that of the LASIK only group (34.56 \pm ) in Tan et al 's study may confound the refractive and keratometric outcomes.

Tan et al found that the predictability of the refractive outcomes in the LASIK Xtra group was statistically significantly greater at 3 months, with a greater coefficient of determination and significant reduction in standard deviation of postoperative spherical equivalent in the LASIK Xtra group $(p=0.005)$. [12] In our study, the standard deviation of postoperative spherical equivalent was comparable in both groups. Our study found a smaller proportion of LASIK Xtra eyes within \pm 0.50 D of the attempted correction compared to LASIK only eyes at post-operative month 3 , and this decreased slightly at post-operative months 6-12. The lower predictability in the LASIK Xtra group was due to a more hyperopic correction achieved compared to the LASIK only group. This may be due to an additional flattening effect of the cornea from CXL. Although the LASIK Xtra group had a lower predictability, subjects in the group had better visual acuity as compared to those in the LASIK only group due to the hyperopic effect.

Other studies have found that LASIK Xtra may provide the additional advantages of refractive and keratometric stability after LASIK. $[12,13]$ Kanellopoulos et al found a reduced refractive shift in the LASIK Xtra eyes compared to LASIK only eyes, though not statistically significant $(p=0.063)$. The mean postoperative Manifest Refraction Spherical Equivalent (MRSE) at postoperative year 1 was $-0.19 \pm 0.17$ D in LASIK Xtra eyes and $-0.27 \pm 0.23$ D in LASIK only eyes. [13] Tan et al similarly reported a trend towards reduced refractive drift in LASIK Xtra eyes (-0.04 D) compared to the LASIK only eyes $(-0.13 \mathrm{D})(p=0.051)$. [12] Furthermore, Kanellopoulos et al reports that corneal keratometry results were stable for LASIK Xtra eyes and slightly regressing in LASIK only eyes $(p=0.039)$. [13] Our study revealed a slightly more hyperopic post-operative result in LASIK Xtra eyes $(+0.36 \pm 0.42 \mathrm{D})$ compared to LASIK only eyes $(+0.15 \pm 0.44 \mathrm{D})$ at post-operative 3 months (Table 1). However, LASIK Xtra eyes were found to achieve good refractive stability and less regression with spherical equivalent of $+0.35 \pm 0.45 \mathrm{D}$ at post-operative 6 to 12 months (Fig. 1). This finding may support the concept postulated by Tan et al of a CXL-induced early stabilization of the cornea following corneal wavefront-guided stromal ablation. [12] The lack of longer term follow-up data for the LASIK only group limited comparison between the groups for refractive stability.

The LASIK Xtra group in our study showed a good safety profile. One Snellen line decrease in CDVA was found in $5(10.0 \%)$ LASIK Xtra eyes at post-operative 3 months, which may be due to postoperative corneal haze. The corneal haze in these eyes resolved in 3 out of 5 eyes by post-operative 6 to 12 months ( 2 eyes lost to follow-up).

Limitations of the study include a relatively high rate of subjects lost to follow-up and short term follow-up period, which is typical of patients undergoing keratorefractive surgery, precluding long-term follow-up. Corneal biomechanical properties were not measured in this study. Corneal hysteresis and corneal resistance factor, measured by the Ocular Response Analyzer (Reichert Ophthalmic Instruments, Buffalo, New York, USA), before and after corneal CXL were found to have no statistically significant difference. [21, 22]

\section{CONCLUSION}

In conclusion, LASIK Xtra achieved comparable visual outcomes compared to LASIK in Asians with high myopia in terms of safety, predictability and efficacy. Good refractive stability was attained at 6-12 months for LASIK Xtra. Further long term studies are required to determine whether simultaneous CXL is able to reduce postoperative LASIK 
keratectasia in high-risk individuals.

\section{ETHICS APPROVAL AND CONSENT TO PARTICIPATE}

The study was approved by the SingHealth Centralised Institutional Review Board.

\section{HUMAN AND ANIMAL RIGHTS}

No Animals were used in this research. All human research procedures followed were in accordance with the ethical standards of the committee responsible for human experimentation (institutional and national), and with the Helsinki Declaration of 1975 , as revised in 2013.

\section{CONSENT OF PUBLICATION}

A written informed consent was taken from the patent when they were enrolled.

\section{CONFLICT OF INTERESTS}

The authors declare no conflict of interest, financial or otherwise.

\section{ACKNOWLEDGEMENTS}

J.R.L. was involved in data collection, analysis and interpretation of data, and writing the manuscript. L.L. was involved in conception and design, analysis and interpretation of data, critical revision of the manuscript, and supervision. J.C.W.K. was involved in data collection, analysis and interpretation of data, writing the manuscript, and statistical expertise. D.K.P.C. was involved in conception and design, data collection, and writing the manuscript. M.R. was involved in conception and design, analysis and interpretation of data, and critical revision of the manuscript.

\section{REFERENCES}

[1] Shortt AJ, Allan BDS, Evans JR. Laser-Assisted In-situ Keratomileusis (LASIK) versus Photorefractive Keratectomy (PRK) for myopia. Cochrane Database Syst Rev 2013; (1): CD005135. [PMID: 23440799]

[2] Hafezi F, Kanellopoulos J, Wiltfang R, Seiler T. Corneal collagen crosslinking with riboflavin and ultraviolet A to treat induced keratectasia after laser in situ keratomileusis. J Cataract Refract Surg 2007; 33(12): 2035-40. [http://dx.doi.org/10.1016/j.jcrs.2007.07.028] [PMID: 18053900]

[3] Randleman JB, Trattler WB, Stulting RD. Validation of the ectasia risk score system for preoperative laser in situ keratomileusis screening. Am J Ophthalmol 2008; 145(5): 813-8. [http://dx.doi.org/10.1016/j.ajo.2007.12.033] [PMID: 18328998]

[4] Woodward MA, Randleman JB, Russell B, Lynn MJ, Ward MA, Stulting RD. Visual rehabilitation and outcomes for ectasia after corneal refractive surgery. J Cataract Refract Surg 2008; 34(3): 383-8. [http://dx.doi.org/10.1016/j.jcrs.2007.10.025] [PMID: 18299061]

[5] Wittig-Silva C, Whiting M, Lamoureux E, Lindsay RG, Sullivan LJ, Snibson GR. A randomized controlled trial of corneal collagen crosslinking in progressive keratoconus: Preliminary results. J Refract Surg 2008; 24(7): S720-5. [PMID: 18811118]

[6] Vinciguerra P, Camesasca FI, Albè E, Trazza S. Corneal collagen cross-linking for ectasia after excimer laser refractive surgery: 1-year results. J Refract Surg 2010; 26(7): 486-97. [http://dx.doi.org/10.3928/1081597X-20090910-02] [PMID: 19772221]

[7] Salgado JP, Khoramnia R, Lohmann CP, Winkler von Mohrenfels C. Corneal collagen crosslinking in post-LASIK keratectasia. Br J Ophthalmol 2011; 95(4): 493-7.

[http://dx.doi.org/10.1136/bjo.2010.179424] [PMID: 20679077]

[8] Kymionis GD, Bouzoukis D, Diakonis V, et al. Long-term results of thin corneas after refractive laser surgery. Am J Ophthalmol 2007; 144(2): 181-5. [http://dx.doi.org/10.1016/j.ajo.2007.04.010] [PMID: 17533106]

[9] Kanellopoulos AJ, Binder PS. Management of corneal ectasia after LASIK with combined, same-day, topography-guided partial transepithelial PRK and collagen cross-linking: The athens protocol. J Refract Surg 2011; 27(5): 323-31. [http://dx.doi.org/10.3928/1081597X-20101105-01] [PMID: 21117539]

[10] Spoerl E, Mrochen M, Sliney D, Trokel S, Seiler T. Safety of UVA-riboflavin cross-linking of the cornea. Cornea 2007; 26(4): 385-9. [http://dx.doi.org/10.1097/ICO.0b013e3180334f78] [PMID: 17457183]

[11] Kymionis GD, Grentzelos MA, Kankariya VP, et al. Safety of high-intensity corneal collagen crosslinking. J Cataract Refract Surg 2014; 40(8): 1337-40. 
[http://dx.doi.org/10.1016/j.jcrs.2013.11.041] [PMID: 25088634]

[12] Tan J, Lytle GE, Marshall J. Consecutive laser in situ keratomileusis and accelerated corneal crosslinking in highly myopic patients: Preliminary results. Eur J Ophthalmol 2014. Dec 5:0.

[13] Kanellopoulos AJ, Asimellis G, Karabatsas C. Comparison of prophylactic higher fluence corneal cross-linking to control, in myopic LASIK, one year results. Clin Ophthalmol 2014; 8: 2373-81. [http://dx.doi.org/10.2147/OPTH.S68372] [PMID: 25473264]

[14] Tomita M. Combined laser in situ keratomileusis and accelerated corneal cross-linking: An update. Curr Opin Ophthalmol 2016; 27(4): 304-10.

[http://dx.doi.org/10.1097/ICU.0000000000000281] [PMID: 27152484]

[15] Chen Y-I, Chien K-L, Wang I-J, et al. An interval-censored model for predicting myopic regression after laser in situ keratomileusis. Invest Ophthalmol Vis Sci 2007; 48(8): 3516-23. [http://dx.doi.org/10.1167/iovs.06-1044] [PMID: 17652718]

[16] Chayet AS, Assil KK, Montes M, Espinosa-Lagana M, Castellanos A, Tsioulias G. Regression and its mechanisms after laser in situ keratomileusis in moderate and high myopia. Ophthalmology 1998; 105(7): 1194-9. [http://dx.doi.org/10.1016/S0161-6420(98)97020-8] [PMID: 9663221]

[17] Raiskup-Wolf F, Hoyer A, Spoerl E, Pillunat LE. Collagen crosslinking with riboflavin and ultraviolet-A light in keratoconus: Long-term results. J Cataract Refract Surg 2008; 34(5): 796-801. [http://dx.doi.org/10.1016/j.jcrs.2007.12.039] [PMID: 18471635]

[18] Wittig-Silva C, Chan E, Islam FM, Wu T, Whiting M, Snibson GR. A randomized, controlled trial of corneal collagen cross-linking in progressive keratoconus: Three-year results. Ophthalmology 2014; 121(4): 812-21. [http://dx.doi.org/10.1016/j.ophtha.2013.10.028] [PMID: 24393351]

[19] Tomita M, Yoshida Y, Yamamoto Y, Mita M, Waring G IV. In vivo confocal laser microscopy of morphologic changes after simultaneous LASIK and accelerated collagen crosslinking for myopia: One-year results. J Cataract Refract Surg 2014; 40(6): $981-90$. [http://dx.doi.org/10.1016/j.jcrs.2013.10.044] [PMID: 24857441]

[20] Celik HU, Alagöz N, Yildirim Y, et al. Accelerated corneal crosslinking concurrent with laser in situ keratomileusis. J Cataract Refract Surg 2012; 38(8): 1424-31.

[http://dx.doi.org/10.1016/j.jcrs.2012.03.034] [PMID: 22814049]

[21] Vinciguerra P, Albè E, Mahmoud AM, Trazza S, Hafezi F, Roberts CJ. Intra- and postoperative variation in ocular response analyzer parameters in keratoconic eyes after corneal cross-linking. J Refract Surg 2010; 26(9): 669-76. [http://dx.doi.org/10.3928/1081597X-20100331-01] [PMID: 20438025]

[22] Meek KM, Boote C. The use of X-ray scattering techniques to quantify the orientation and distribution of collagen in the corneal stroma. Prog Retin Eye Res 2009; 28(5): 369-92.

[http://dx.doi.org/10.1016/j.preteyeres.2009.06.005] [PMID: 19577657]

(C) 2018 Low et al.

This is an open access article distributed under the terms of the Creative Commons Attribution 4.0 International Public License (CC-BY 4.0), a copy of which is available at: (https://creativecommons.org/licenses/by/4.0/legalcode). This license permits unrestricted use, distribution, and reproduction in any medium, provided the original author and source are credited. 